\title{
MAPEAMENTO E CARACTERIZAÇÃO DE FEIÇÕES CÁRSTICAS DE SUPERFÍCIE NA FAIXA ITAIACOCA NAS REGIÕES DE NOVA CAMPINA E BOM SUCESSO DE ITARARÉ, SP/PR
}

\author{
Silvio Takashi HIRUMA \\ José Antonio FERRARI \\ Rosangela do AMARAL \\ Rafael Fernando HONÓRIO
}

\begin{abstract}
RESUMO
O trabalho apresenta uma caracterização de feições cársticas de superfície identificadas a partir de fotointerpretação de detalhe (1:25.000) nos terrenos carbonáticos da Faixa Itaiacoca nas regiões de Nova Campina e Bom Sucesso de Itararé, estados de São Paulo e Paraná. As maiores concentrações de sumidouros e depressões fechadas situam-se próximas às áreas urbanas de Nova Campina e de Bom Sucesso de Itararé e no extremo sudoeste da área estudada, já no Estado do Paraná. Nessas áreas identifica-se o desenvolvimento do padrão de carste poligonal, semelhante ao descrito na Bacia do Rio Betari, no Alto Vale do Ribeira. A análise morfométrica das depressões fechadas revelou que, em geral, apresentam área, perímetro, amplitude e declividade inferiores aos observados nas faixas Lajeado e André Lopes, no Vale do Ribeira; índices de circularidade, no entanto, são maiores. Considerando-se a área total de captação das depressões, foi possível estimar que a contribuição da recarga autóctone é expressivamente mais importante que a alóctone na Faixa Itaiacoca. A diversidade do uso e ocupação do solo na área demanda um planejamento adequado para proteção do carste. O mapeamento e caracterização de feições cársticas apresentados nesse estudo constituem a base para estudos futuros sobre a dinâmica hidrológica subterrânea dos sistemas cársticos da região.
\end{abstract}

Palavras-chave: carste, depressões fechadas, Faixa Itaiacoca, Nova Campina, Bom Sucesso de Itararé

\section{ABSTRACT}

This paper presents a characterization of surface karst features identified by detailed aerial photo interpretation (1:25.000) of the carbonate terrains of the Itaiacoca Belt in the Nova Campina and Bom Sucesso de Itararé regions, São Paulo and Paraná. The main concentrations of sinkholes and closed depressions occur within the urban areas of Nova Campina and Bom Sucesso de Itarare and in the southwestern part of the studied area in the State of Paraná. In these areas a polygonal karst pattern, similar to that observed in the Betari River Basin, Upper Ribeira Valley, is present. Morphometric analysis revealed that the closed depressions in general present lower values for area, perimeter, amplitude and slope than those observed in the Lajeado and André Lopes belts (Ribeira Valley); circularity indices are higher. Considering the total catchment area of the closed depressions, it was possible to estimate that autochthonous recharge is more important than allochthonous recharge. Diversified land use and occupation in the area require appropriate planning in order to protect the karst. Mapping and characterization of karst features presented in this study constitute the basis for future studies related to the subterranean hydrologic dynamics of karst systems of the region.

Keywords: karst, closed depressions, Itaiacoca Belt, Nova Campina, Bom Sucesso de Itararé 


\section{INTRODUÇÃO}

O epicarste é definido como a zona superior de rochas carstificáveis, onde a permeabilidade devido ao fissuramento e a carstificação é substancialmente mais alta e mais uniformemente distribuída quando comparada com a massa rochosa subjacente (KLIMCHOUK 2004). Sua espessura varia de poucos centímetros a dezenas de metros. Do ponto de vista hidrológico, as funções do epicarste são o armazenamento e a concentração do fluxo (FORD \& WILLIAMS 1989). Em áreas de carste coberto, as depressões fechadas são a melhor expressão da presença do epicarste, no entanto, este pode ser altamente desenvolvido, mesmo sem a presença de qualquer feição de superfície.

O solo e os sedimentos no epicarste, dependendo de seus atributos, funcionam como barreira, com diferentes níveis de eficácia, na proteção da água subterrânea contra contaminantes despejados em superfície. Contudo, quando depressões fechadas concentram o escoamento superficial em pontos de absorção, a barreira protetora é completamente ignorada e contaminantes podem ser rapidamente carreados para o aqüífero. Neste contexto, o mapeamento de depressões fechadas é etapa fundamental para o planejamento de recursos hídricos em regiões cársticas.

Os terrenos carbonáticos da Faixa Itaiacoca (Proterozóico) nas regiões de Nova Campina e Bom Sucesso de Itararé compõem uma faixa de direção geral NE-SW, concordante com a estruturação geo- lógica pré-cambriana regional, limitando-se a noroeste pela cobertura sedimentar da bacia do Paraná e a sudeste pelo Lineamento Itapirapuã (KARMANN 1994, Figura 1). A presente contribuição tem por finalidade apresentar uma caracterização morfológica preliminar do carste da região, com ênfase nas depressões fechadas, dada sua importância para o uso sustentável dos recursos hídricos. Embora ocorrências de feições cársticas, como cavernas e depressões fechadas, já tenham sido referidas nessa região em trabalhos anteriores (SOUZA 1990, GENTHNER et al. 2001, GEEP/AÇUNGUI 1999, GPME 2005), um levantamento sistemático das feições cársticas de superfície ainda não havia sido realizado.

A área de estudo estende-se do sul do município de Itapeva (SP) até o norte de Doutor Ulysses (PR), com destaque para as regiões de Nova Campina e Bom Sucesso de Itararé (SP) (Figura 1), e compreende parte das cabeceiras da bacia hidrográfica do Rio Paranapanema.

Esse levantamento permite traçar diretrizes para estudos futuros de maior detalhe sobre a dinâmica hidrológica subterrânea dos sistemas cársticos na Faixa Itaiacoca. Além disso, fornece subsídios para a aplicação da Resolução SMA-56 de 27/12/2006, que estabelece o grau de impacto ambiental em empreendimentos de grande porte, para fins de cobrança de compensação ambiental. Um dos critérios considerados na análise é a existência de cavernas ou fenômenos cársticos, tais como depressões fechadas, sumidouros, ressurgências e condutos.
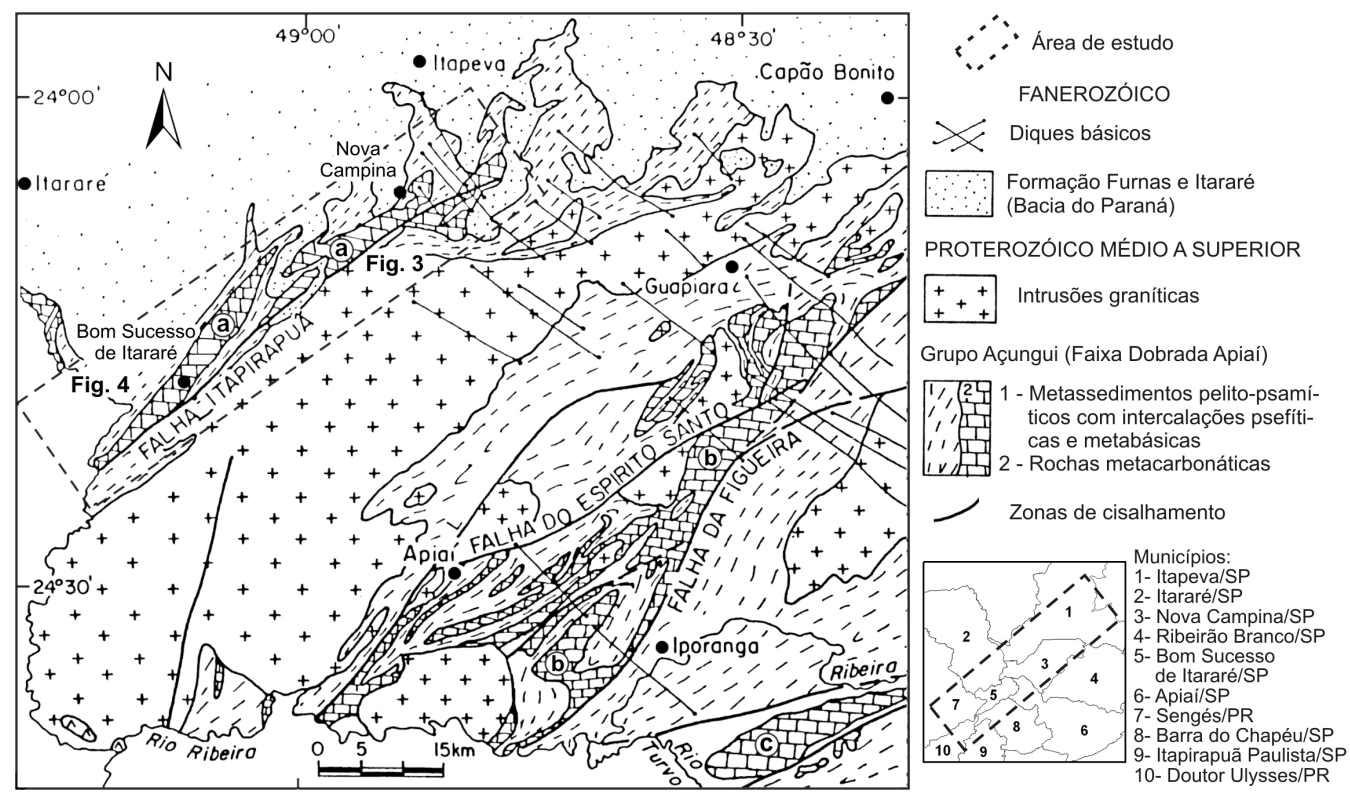

FIGURA 1: Contexto geológico da área de estudo (modificado de KARMANN, 1994). Faixas carbonáticas: (a) Itaiacoca, (b) Lajeado, (c) André Lopes. Estão indicadas as localizações aproximadas das figuras 3 e 4. 


\section{METODOLOGIA}

A partir da fotointerpretação de detalhe, em escala 1:25.000 (Levantamento aerofotogramétrico da Secretaria da Agricultura, 1972), foram traçados os divisores de água, sumidouros e cones cársticos, conforme procedimentos descritos em KARMANN (1994). Após a etapa de fotointerpretação, os dados foram transferidos para uma base cartográfica em formato digital, elaborada a partir da montagem de folhas topográficas do IBGE escala 1:50.000 - Ouro Verde (1975), Barra do Chapéu (1975), Engenheiro Maia (1975), Ribeirão Branco (1975) e Guapiara (1974). Levantamentos de campo foram efetuados para reconhecimento de feições identificadas na fotointerpretação.

Para fins de classificação, foram consideradas autóctones as depressões fechadas que drenam exclusivamente terrenos carbonáticos, e alóctones, aquelas com contribuição mista, em que parte da drenagem provem de litologias não carbonáticas. Também foram consideradas as bacias associadas ao carste subjacente (EPA 2002), que ocorrem em litologias não carbonáticas. Neste caso, o desenvolvimento de carste nas rochas carbonáticas, abaixo de rochas siliciclásticas, promoveu a subsidência das rochas de cobertura.

Dados de imageamento de radar, com resolução de $90 \mathrm{~m}$, disponibilizados no site do U.S. Geological Survey, EROS Data Center, Sioux Falls, SD (http:// seamless.usgs.gov) foram utilizados para a elaboração de modelos digitais de terreno e extração de parâmetros morfométricos.

A análise morfométrica baseou-se nos trabalhos de KARMANN (1994) e FERRARI et al. (1998) e teve por finalidade obter uma assinatura quantitativa do carste, favorecendo a comparação de paisagens envolvidas em contextos climáticos ou estruturais diferenciados. Os seguintes parâmetros morfométricos foram considerados na análise: densidade de sumidouros, área, índice de circularidade, amplitude e declividade das depressões fechadas. Para a análise das depressões, estas foram separadas segundo o tipo de recarga. Comparações foram efetuadas com dados morfométricos de outras regiões de carste poligonal.

\section{CONTEXTO REGIONAL}

Os terrenos cársticos das bacias hidrográficas dos rios Ribeira e Paranapanema, representados pelas faixas carbonáticas Itaiacoca, Lajeado e André Lopes (KARMANN 1994), inserem-se no contexto geológico da Faixa Dobrada Apiaí, composta pela seqüência metassedimentar supra-crustal vulcano-sedimentar
(Grupo Açungui), compartimentada em blocos tectônicos separados por zonas de cisalhamento transcorrentes de direção NE-SW (CAMPANHA 1991). Das três faixas carbonáticas, a Faixa Lajeado, na região do Vale do Rio Betari, é a mais estudada quanto a evolução e dinâmica dos sistemas cársticos; nas demais faixas, ainda faltam estudos regionais que sintetizem suas feições principais.

Os terrenos carbonáticos da Faixa Itaiacoca, representados predominantemente por metacalcários dolomíticos, estão inseridos geomorfologicamente no Planalto de Guapiara, que ocupa a região elevada da Serra de Paranapiacaba, estendendo-se até as áreas cobertas pelos sedimentos da Bacia do Paraná (PONÇANO et al. 1981), separando a Província Costeira da Depressão Periférica. Para fins de melhor representação gráfica e discussão dos dados, a Faixa Itaiacoca foi dividida em dois segmentos principais, que apresentam as maiores concentrações de feições cársticas (figuras 3 e 4): Nova Campina (a norte), compreendendo também parte do município de Itapeva, e Bom Sucesso de Itararé (a sul), abrangendo parte dos municípios de Doutor Ulysses e Sengés (PR).

Na região de Nova Campina, a faixa carbonática ocupa áreas de interflúvios e topos de morros, com altitudes variando entre 700 e $900 \mathrm{~m}$ (Fig. 2A e B); é recortada transversalmente por diversos rios que fazem parte da Bacia do Rio Paranapanema, entre eles, o Rio Taquari-Guaçu, Rio Taquari-Mirim e o Rio Apiaí-Guaçu, que abastece o Reservatório da Usina da Barra e a Usina Hidrelétrica de Santa Maria.

O limite entre o Planalto de Guapiara e a Depressão Periférica na região de Bom Sucesso de Itararé é bem caracterizado pelas escarpas devonianas da Formação Furnas. A superfície cárstica nesta região ocupa uma porção deprimida - 800 a $1000 \mathrm{~m}$ - em relação às escarpas do arenito Furnas $(1100 \mathrm{a} 1200 \mathrm{~m})$ a noroeste e às serras quartzíticas de Itapirapuã e Bom Sucesso, que atingem mais de $1200 \mathrm{~m}$, a sudeste (Figura 2A, C e D). Suas porções nordeste e central são drenadas pelas nascentes dos rios Pirituba e Itararé, afluentes do Rio Paranapanema, enquanto que a porção sul, pelas nascentes do Rio Itapirapuã, que desemboca no Rio Ribeira de Iguape. Comparativamente, os rios que drenam os terrenos carbonáticos em Bom Sucesso de Itararé são de menor ordem hierárquica que os de Nova Campina. Ressalta-se que nos trabalhos de campo, realizados durante o inverno, trechos de rios importantes a sudeste de Bom Sucesso de Itararé apresentavam leito seco. 

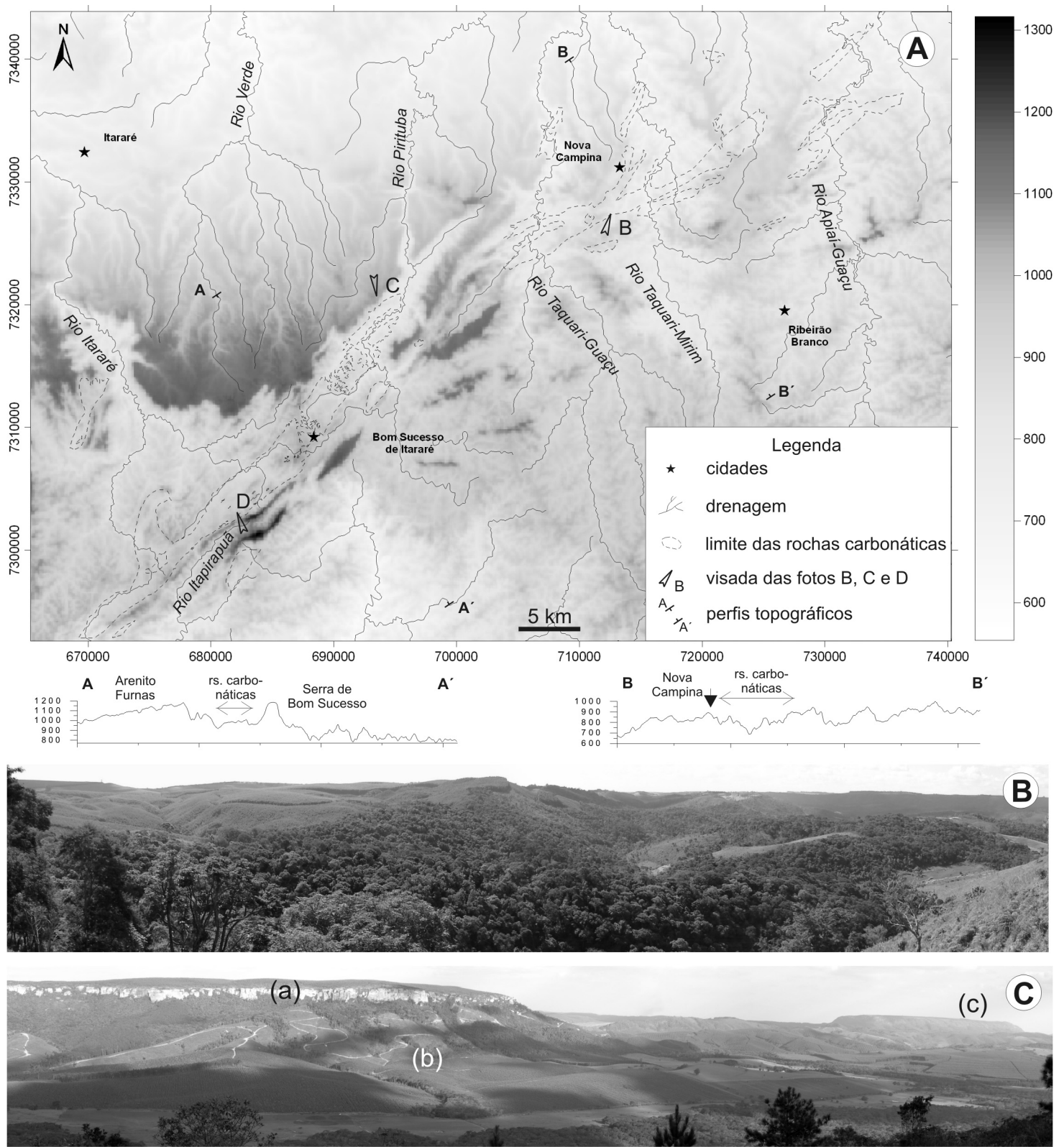

(c)

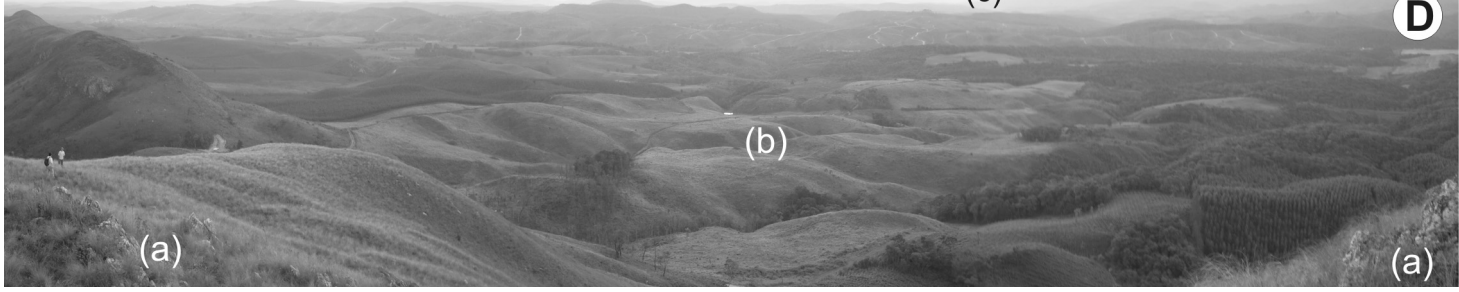

FIGURA 2: Contexto regional da Faixa Itaiacoca. A) Mapa hipsométrico (em metros) da área de estudo e perfis topográficos transversais aos terrenos carbonáticos. Limite das rochas carbonáticas (em tracejado) extraído de IG (inédito). Coordenadas UTM, zona 23K. B) Vista geral da paisagem dos terrenos carbonáticos, próximo à cidade de Nova Campina, em parte, recobertos por reflorestamento (ao fundo). C) Vista do vale do Rio Pirituba: (a) escarpa do arenito Furnas; (b) rochas carbonáticas; (c) serra quartzítica de Bom Sucesso. D) (a) em primeiro plano, Serra de Itapirapuã (quartzitos); (b) zona rebaixada onde afloram os terrenos carbonáticos; (c) ao fundo, relevo escarpado do arenito Furnas. 
Na região de Nova Campina predominam os Cambissolos Háplicos associados aos Latossolos Vermelho-Amarelos e subordinadamente Latossolos Vermelho-Amarelos, ambos com textura argilosa, enquanto que na região de Bom Sucesso de Itararé, a faixa carbonática é recoberta pelos Argissolos Vermelhos de textura argilosa; em seu entorno predominam os Neossolos Litólitos de textura arenosa (OLIVEIRA et al. 1999).

O uso e ocupação do solo na Faixa Itaiacoca é bastante diversificado, com culturas variadas, pastagens, reflorestamento de pinus e de eucalipto, fragmentos de mata e importantes minerações de calcário.

\section{FEIÇÕES CÁRSTICAS DA FAIXA ITAIACOCA}

A partir dos dados levantados, verificou-se que a distribuição das feições cársticas ao longo da Faixa Itaiacoca não é uniforme (Figuras 3 e 4). Comparando-se com o carste da região do Alto Ribeira (KARMANN \& SANCHEZ 1979, KARMANN 1994, KARMANN \& FERRARI 2002),

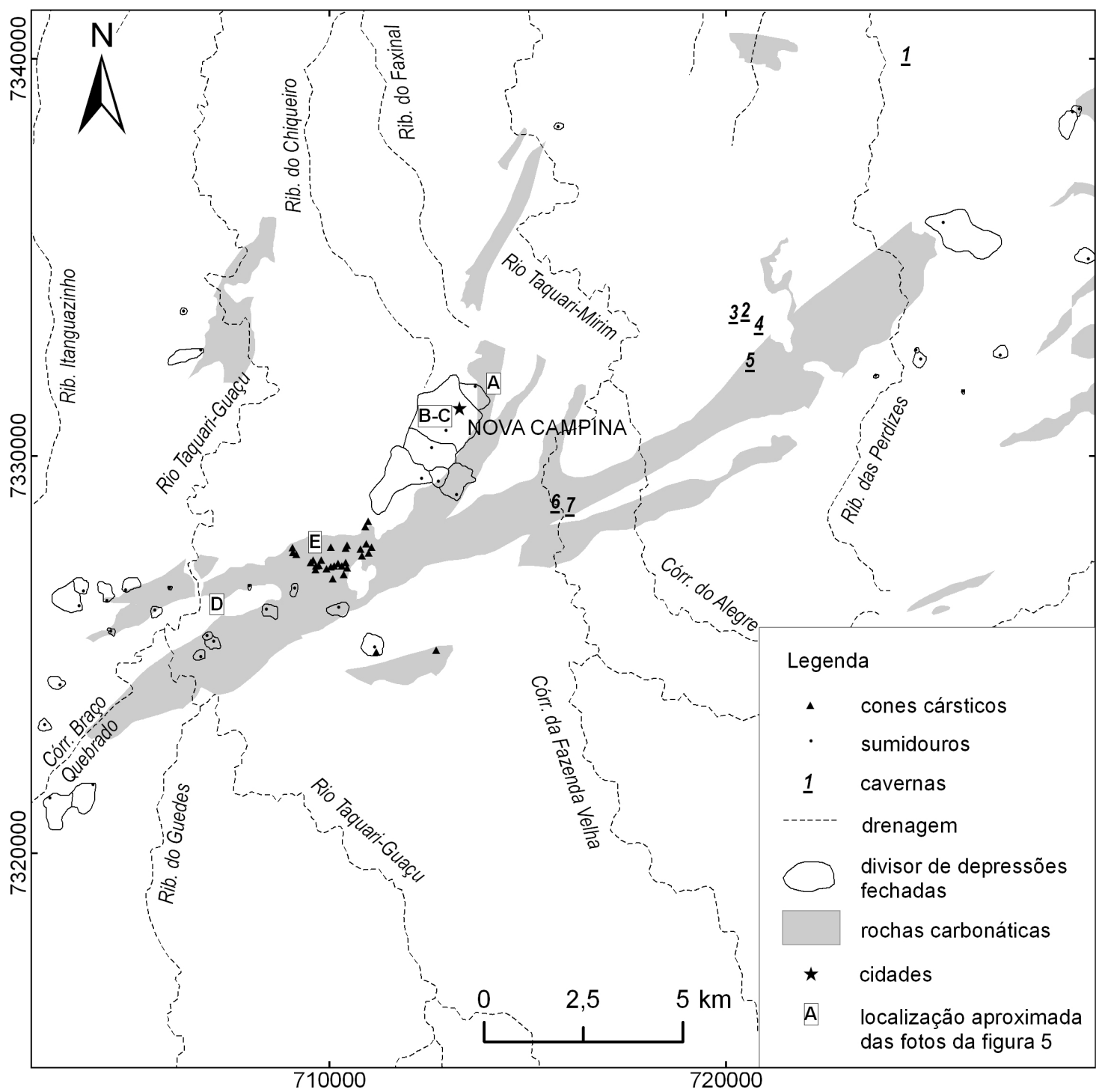

FIGURA 3: Mapa de feições cársticas da região de Nova Campina (Coordenadas UTM, zona 23K). Cavernas desenvolvidas em arenito: 1 - Caverna San Raphael, 2 - Fenda 1, 3 - Fenda 2, 4 - Casa de Pedra de Itapeva. Cavernas desenvolvidas em calcário: 5 - Gruta do Aldo, 6 - Gruta do Taquari-Mirim, 7 - Gruta do Abelheiro (Fonte: GPME 2005). Limite das rochas carbonáticas extraído de IG (inédito). 


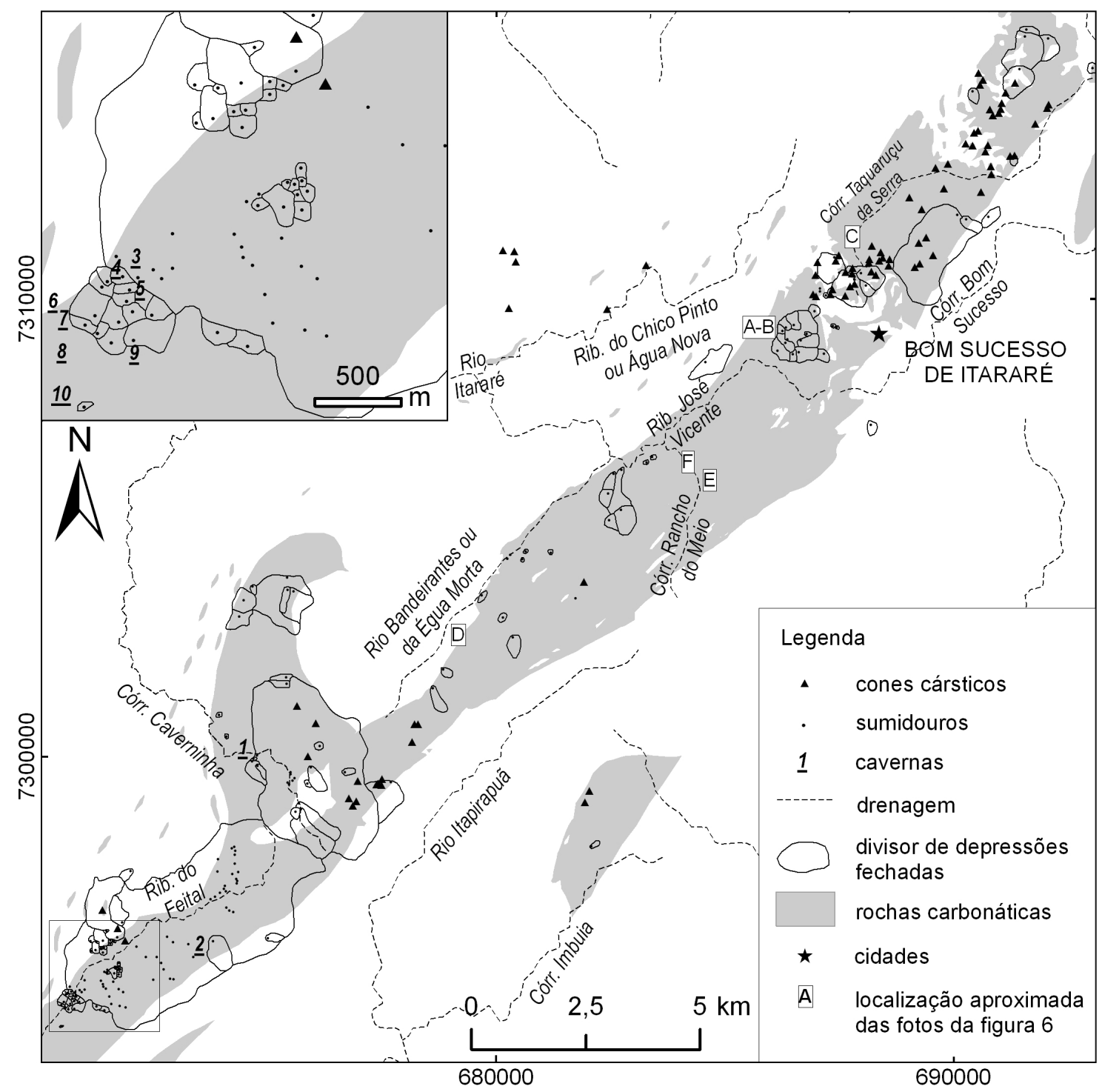

FIGURA 4: Mapa de feições cársticas da região de Bom Sucesso de Itararé (Coordenadas UTM, zona 23K). Em maior detalhe (no canto superior esquerdo), a porção sudoeste da área de estudo, caracterizada por uma elevada densidade de sumidouros. Cavernas desenvolvidas em calcário: 1 - Gruta do Pinhalzinho, 2 - Gruta do Pocinho, 3 -Gruta Casa de Pedra, 4 - Gruta Buraco do Vento, 5 - Buraco do Cláudio, 6 - Gruta da Caverninha, 7 - Gruta Dá a Volta, 8 - Gruta Cão Paraná, 9- Gruta Arco do Pé, 10 - Gruta da Ressurgência do Feital (Fonte: GEEP/AÇUNGUI 1999). Limite das rochas carbonáticas extraído de IG (inédito).

a área de estudo apresenta, de modo geral, uma menor densidade de feições cársticas. O padrão de carste poligonal, semelhante ao descrito por KARMANN (1994) no vale do Rio Betari, ocorre em porções restritas, apresentando amplitudes de poucas dezenas de metros. Esse padrão é típico de paisagens sobre rochas carbonáticas, onde o escoamento superficial, de natureza essencialmente autóctone, é totalmente absorvido por sumidouros localizados nos fundos de de- pressões delimitadas por divisores, que formam um padrão planimétrico poligonal. Gradientes hidráulicos são pouco expressivos na Faixa Itaiacoca; feições como cânions cársticos e paredões rochosos não são comuns.

A tabela 1 sintetiza os parâmetros morfométricos obtidos para os diferentes tipos de depressões fechadas da Faixa Itaiacoca.

Em geral, as depressões fechadas possuem perímetro, área, amplitude e declividade inferiores 
TABELA 1: Parâmetros morfométricos das depressões fechadas da Faixa Itaiacoca. N.C. $=$ Nova Campina, B.S.I = Bom Sucesso de Itararé, DP = desvio padrão.

\begin{tabular}{|c|c|c|c|c|c|c|c|c|c|c|}
\hline \multirow{2}{*}{\multicolumn{2}{|c|}{$\begin{array}{c}\text { Faixa } \\
\text { Itaiacoca }\end{array}$}} & \multicolumn{3}{|c|}{$\begin{array}{c}\text { depressões fechadas } \\
\text { autóctones } \\
(\text { total }=84)\end{array}$} & \multicolumn{3}{|c|}{$\begin{array}{c}\text { depressões fechadas } \\
\text { alóctones } \\
(\text { total }=39)\end{array}$} & \multicolumn{3}{|c|}{$\begin{array}{c}\text { depressões } \\
\text { fechadas associadas } \\
\text { ao carste subjacente } \\
(\text { total }=26)\end{array}$} \\
\hline & & geral & $\begin{array}{l}\text { N.C. } \\
\text { (11) }\end{array}$ & $\begin{array}{c}\text { B.S.I. } \\
(73)\end{array}$ & geral & $\begin{array}{c}\text { N.C. } \\
\text { (7) }\end{array}$ & $\begin{array}{l}\text { B.S.I. } \\
(32)\end{array}$ & geral & $\begin{array}{l}N . C . \\
(19)\end{array}$ & $\begin{array}{c}\text { B.S.I. } \\
\text { (7) }\end{array}$ \\
\hline \multirow{4}{*}{$\begin{array}{l}\text { área } \\
\left(\mathrm{km}^{2}\right)\end{array}$} & $\min$ & 0,0023 & 0,0083 & 0,0023 & 0,0044 & 0,06370 & 0,0044 & 0,0033 & 0,0078 & 0,0033 \\
\hline & $\max$ & 0,4753 & 0,4753 & 0,2685 & 12,5844 & 0,30658 & 12,5844 & 2,0200 & 2,0200 & 0,3447 \\
\hline & média & 0,0490 & 0,0972 & 0,0418 & 0,7553 & 0,17910 & 0,8814 & 0,3120 & 0,3962 & 0,0836 \\
\hline & $\mathrm{DP}$ & 0,0707 & 0,1266 & 0,0542 & 2,2181 & 0,07379 & 2,4303 & 0,4849 & 0,5393 & 0,1118 \\
\hline \multirow{4}{*}{$\begin{array}{c}\text { perímetro } \\
(\mathrm{km})\end{array}$} & $\min$ & 0,183 & 0,336 & 0,183 & 0,281 & 0,951 & 0,281 & 0,220 & 0,336 & 0,220 \\
\hline & $\max$ & 2,989 & 2,958 & 2,989 & 23,046 & 2,246 & 23,046 & 5,908 & 5,908 & 2,745 \\
\hline & média & 0,782 & 1,077 & 0,738 & 2,858 & 1,681 & 3,116 & 1,783 & 2,071 & 1,001 \\
\hline & $\mathrm{DP}$ & 0,577 & 0,692 & 0,544 & 4,248 & 0,423 & 4,646 & 1,584 & 1,701 & 0,793 \\
\hline \multirow{4}{*}{$\begin{array}{l}\text { amplitude } \\
\text { (m) }\end{array}$} & $\min$ & $\sim 0$ & 3,0 & $\sim 0$ & 7,6 & 26 & 7,6 & 0,7 & 0,8 & 0,7 \\
\hline & $\max$ & 105,0 & 71,0 & 105,0 & 199,3 & 146 & 199,3 & 174,2 & 174,2 & 57,1 \\
\hline & média & 24,0 & 27,3 & 23,5 & 68,2 & 80,9 & 65,4 & 61,9 & 74,0 & 28,9 \\
\hline & DP & 21,0 & 18,1 & 21,4 & 49,2 & 40,8 & 49,7 & 52,9 & 56,2 & 19,0 \\
\hline \multirow{4}{*}{$\begin{array}{c}\text { declividade } \\
\text { (graus) }\end{array}$} & $\min$ & $\sim 0$ & 2,0 & $\sim 0$ & 1,8 & 4,0 & 1,8 & 1,5 & 1,5 & 2,2 \\
\hline & $\max$ & 14,0 & 11,0 & 14,0 & 10,5 & 10,0 & 10,5 & 20,9 & 20,9 & 7,4 \\
\hline & média & 4,9 & 4,9 & 4,9 & 5,6 & 7,3 & 5,3 & 6,7 & 7,4 & 4,7 \\
\hline & DP & 2,7 & 2,4 & 2,7 & 2,2 & 2,4 & 2,0 & 4,9 & 5,5 & 1,6 \\
\hline \multirow{4}{*}{$\begin{array}{c}\text { indice de } \\
\text { circularidade }\end{array}$} & $\min$ & 0,38 & 0,68 & 0,38 & 0,30 & 0,59 & 0,30 & 0,55 & 0,55 & 0,58 \\
\hline & $\max$ & 0,93 & 0,93 & 0,93 & 0,93 & 0,88 & 0,93 & 0,95 & 0,95 & 0,86 \\
\hline & média & 0,76 & 0,81 & 0,76 & 0,71 & 0,78 & 0,69 & 0,80 & 0,82 & 0,74 \\
\hline & DP & 0,12 & 0,08 & 0,13 & 0,16 & 0,09 & 0,17 & 0,11 & 0,11 & 0,10 \\
\hline
\end{tabular}

aos observados nas faixas Lajeado e André Lopes, no Vale do Ribeira (HIRUMA et al. 2007); os valores de índices de circularidade, no entanto, são superiores. Comparando-se os diferentes tipos de depressões da Faixa Itaiacoca, observa-se que: as autóctones apresentam em média os menores valores de área, perímetro, amplitude e declividade; as alóctones, os maiores valores de área, perímetro e amplitude e os menores índices de circularidade; as de carste subjacente, os maiores valores de índices de circularidade e de declividade.

Totalizando a área de captação das depressões, foi possível estimar a contribuição dos diferentes tipos de recarga. No caso da recarga alóctone, computou-se apenas a área das depressões sobre rochas não-carbonáticas. Verificou-se que 27,9\% $\left(9,4 \mathrm{~km}^{2}\right)$ da área total das depressões respondem pela recarga alóctone, mais significativa no extremo sudoeste da área de estudo - ao longo do Ribeirão Feital -, enquanto que $72,1 \%\left(24,3 \mathrm{~km}^{2}\right)$ representam contribuição predominantemente autóctone. A contribuição alóctone é pouco expressiva, quando comparada com a observada na região do vale do Rio Betari (KARMANN 1994). Ressalta-se ainda que a área total de depressões associadas ao carste subjacente $\left(8,1 \mathrm{~km}^{2}\right)$ é bem expressiva na Faixa Itaiacoca, principalmente na região de Nova Campina.

As maiores concentrações de depressões fechadas ocorrem próximas às áreas urbanas de Nova Campina (Figura 3) e de Bom Sucesso de Itararé e no extremo sudoeste da área de estudo, nos municípios de Doutor Ulysses e Sengés (Figura 4).

Na região de Nova Campina predominam depressões simples com área planimétrica inferior a $0,4 \mathrm{~km}^{2}$, apresentando drenagem interna formada predominantemente por canais incipientes de até segunda ordem, restritas às áreas de cabeceiras dos afluentes dos rios principais (Figura 3 e 5A); em alguns casos ocorrem isoladas em topos de morros. Em geral, o fundo das depressões é plano, colmatado por sedimentos, não se distinguindo pontos de injeção concentrada. Em geral, a densidade de sumidouros é baixa ( 0 a 5 sumidouros $/ \mathrm{km}^{2}$ ).

As depressões associadas ao carste subjacente apresentam dimensões maiores (até $2 \mathrm{~km}^{2}$ ) e ocorrem predominatemente sobre os arenitos da Formação Furnas, próximas ao contato com as rochas carbonáticas. É o caso, por exemplo, do conjunto de depressões mais importante da área, localizada na zona urbana de Nova Campina (Figura 3), 

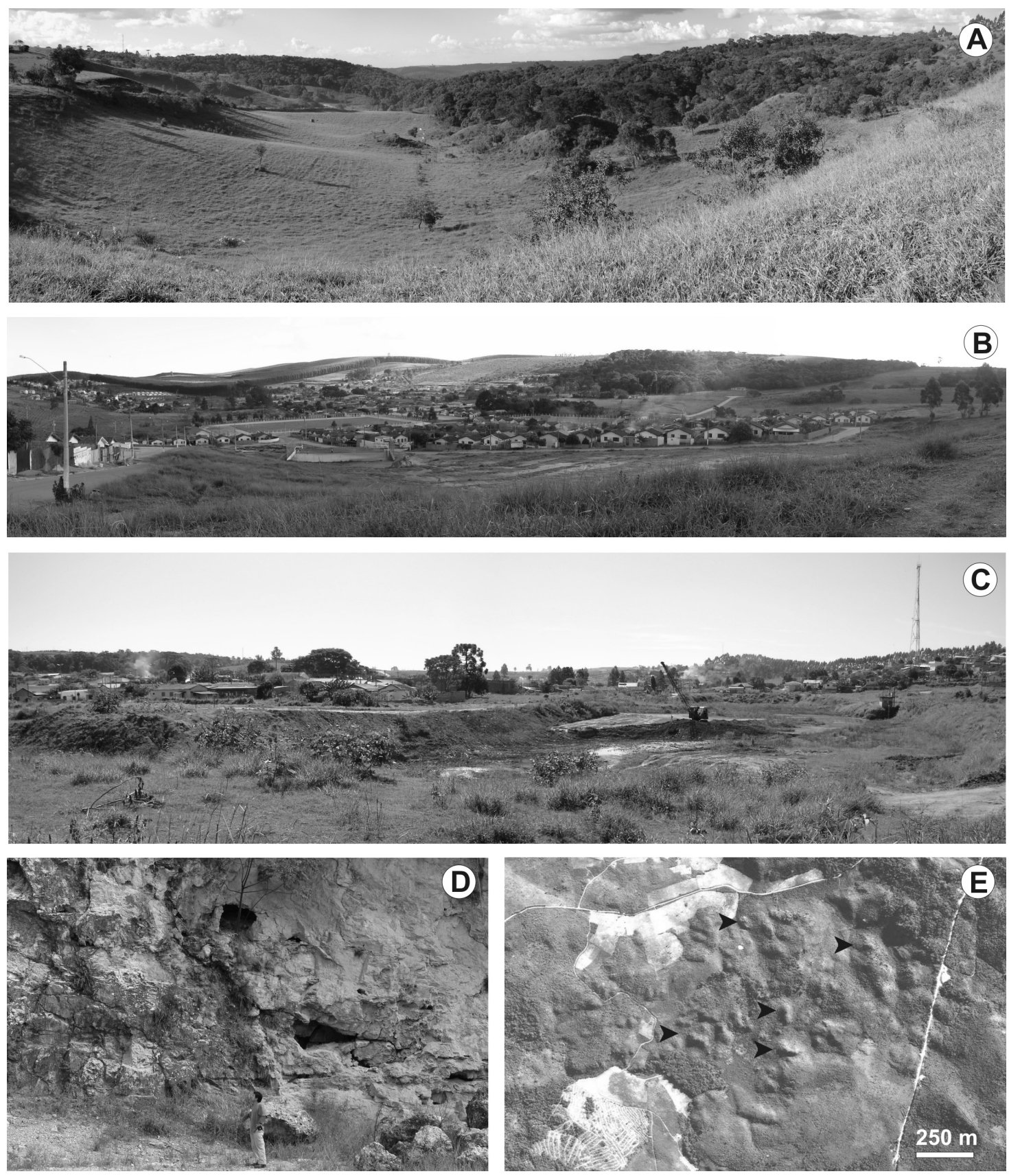

FIGURA 5: Feições cársticas da região de Nova Campina. A - Depressões fechadas de baixa amplitude, colmatadas por sedimentos, a norte da cidade de Nova Campina. B - Vista da área urbana da cidade de Nova Campina, implantada sobre um conjunto de depressões fechadas suaves. C - Obra para contenção de enchentes na área urbana de Nova Campina. A cidade depende de um sistema de bombeamento (à direita da foto) para evitar enchentes em épocas chuvosas. D - Feições de condutos em pedreira, a sudoeste da área urbana de Nova Campina. E - Fotografia aérea na escala 1:25.000, mostrando feições tipo cones/torres cársticos (indicadas por setas), a sul da área urbana de Nova Campina. A localização aproximada das fotos A-E está indicada na figura 3.

com amplitudes de até $100 \mathrm{~m}$ (Figura 5B). A cidade sofre um problema crônico de enchentes durante as épocas chuvosas, contando com um sistema de bombeamento que leva o excesso de água acumulado nas depressões para a bacia do Rio TaquariMirim. Obras de aprofundamento das depressões 
TABELA 2: Cavernas cadastradas na Faixa Itaiacoca, desenvolvidas em rochas metacarbonáticas $(*)$ e arenitos (**). Fonte: GEEP/AÇUNGUI (1999) e GPME (2005).

\begin{tabular}{|c|c|c|c|c|c|}
\hline Nome & Municipio & $\begin{array}{c}\text { Altitude } \\
(\mathrm{m})\end{array}$ & $\begin{array}{c}\text { Desenv. } \\
\text { linear }(\mathrm{m})\end{array}$ & $\begin{array}{c}\text { Projeção } \\
(\mathrm{m})\end{array}$ & $\begin{array}{c}\text { Desnível } \\
(\mathrm{m})\end{array}$ \\
\hline Caverna San Raphael** & Itapeva (SP) & 770 & - & - & - \\
\hline Fenda I* & Itapeva (SP) & 920 & - & - & 22 \\
\hline Fenda II** & Itapeva (SP) & 910 & - & - & - \\
\hline Gruta do Aldo* & Itapeva (SP) & 822 & 127 & 108 & 35 \\
\hline Casa de Pedra de Itapeva** & Nova Campina (SP) & 915 & 52 & 50 & 12 \\
\hline Gruta do Taquari-Mirim* & Nova Campina (SP) & 720 & 140 & 130 & 12,5 \\
\hline Gruta do Abelheiro* & Nova Campina (SP) & 715 & - & - & - \\
\hline Gruta do Pinhalzinho* & Sengés (PR) & 940 & 914 & - & 24 \\
\hline Gruta de Pocinho* & Doutor Ulysses (PR) & 905 & 625 & 590 & 25 \\
\hline Gruta Casa de Pedra* & Doutor Ulysses (PR) & 895 & 72 & 70 & 10 \\
\hline Gruta Buraco do Vento* & Doutor Ulysses (PR) & 893 & 71 & 67 & 14 \\
\hline Buraco do Cláudio* & Doutor Ulysses (PR) & 890 & 32 & 30 & 4 \\
\hline Gruta da Caverninha* & Doutor Ulysses (PR) & 898 & 23 & 20 & 12 \\
\hline Gruta Dá a Volta* & Doutor Ulysses (PR) & 900 & 2675 & 1554 & 51 \\
\hline Gruta Cão Parana** & Doutor Ulysses (PR) & 880 & 130 & 125 & 16 \\
\hline Gruta Arco do Pé* & Doutor Ulysses (PR) & 875 & 175 & 122 & 37 \\
\hline Gruta da Ressurgência do Feital* & Doutor Ulysses (PR) & 870 & 327 & 284 & 28 \\
\hline
\end{tabular}

foram iniciadas para diminuir o impacto das enchentes (Figura 5C).

Em algumas frentes de lavras no município de Itapeva foi possível identificar feições de condutos (Figura 5D) e exemplos didáticos do desenvolvimento do epicarste, que mostram o relevo rochoso irregular recoberto por espesso manto de alteração. Concentração de feições tipo torres/cones cársticos, com amplitude de até $10 \mathrm{~m}$, ocorre predominantemente a sudoeste da cidade de Nova Campina (Figura 3, 5E).

$\mathrm{Na}$ região de Nova Campina, o número de cavernas cadastradas é pouco expressivo, com destaque para as grutas do Taquari-Mirim e do Aldo, com desenvolvimentos, respectivamente, de 140 e $127 \mathrm{~m}$, e desníveis de 12,5 e 35m (GPME 2005). Também foram descritas cavidades formadas em arenito (Figura 3, Tabela 2).

A oeste e norte da região de Bom Sucesso de Itararé ocorrem importantes conjuntos de depressões fechadas e cones cársticos (Figura 4, 6A e 6B). O fundo dessas depressões, em geral, é suave e colmatado por sedimentos, predominando a injeção difusa. No extremo sudoeste da área de estudo (Figura 4), próximo às nascentes do Córrego Caverninha e do Ribeirão do Feital, a densidade de sumidouros atinge valores superiores a 10 sumidouros $/ \mathrm{km}^{2}$ (excepcionalmente 20-25), semelhantes aos observados na área Lajeado - Bombas (Vale do Rio Betari, KARMANN 1994) e no carste de Nova Guiné (WILLIAMS 1972).

As depressões são compostas e em alguns casos, possuem contribuição alóctone, atingindo dimensões de até $12 \mathrm{~km}^{2}$. A rede de drenagem interna é mais complexa, de até quarta ordem, com múltiplos sumidouros, que interrompem os canais de drenagem. Nas nascentes do Ribeirão Feital, não foi possível demarcar os divisores associados aos sumidouros, em função da escala (Figura 4 detalhe). Nessa área são comuns depressões com injeção concentrada, associadas a cavidades naturais. Em algumas pedreiras visitadas, foi possível observar a configuração do epicarste como zona de armazenamento e concentração de fluxo (Fig. 6C).

A região de Pocinho (nordeste de Doutor Ulysses) corresponde à área de maior concentração de cavernas. Nesta área, o Grupo de Estudos Espeleológicos do Paraná (GENTHNER et al. 2001, GEEP/AÇUNGUI 1999) efetuou o mapeamento de 10 cavernas no Sistema Casa de Pedra, formado pelas nascentes do Ribeirão Feital, afluente do Rio Itapirapuã (Tabela 2), com destaque para a Gruta Dá a Volta, com desenvolvimento linear de 2.675 $\mathrm{m}$ e desnível de $51 \mathrm{~m}$.

Na região de Bom Sucesso de Itararé foi possível identificar em campo processos de dolinamento recentes, não identificáveis nas fotografias aéreas (Figura 6D), provocados por colapso do material de cobertura; apresentam profundidade de 0,5 a $1 \mathrm{~m}$ e estão colmatadas por sedimentos. Também é comum a presença de vales secos (Figura 6E) ou com drenagem intermitente, como em alguns setores e afluentes do Ribeirão Feital, Córrego Caverninha e Ribeirão José Vicente. Uma ressurgência ocorre ao longo da Bacia do Córrego Rancho do Meio (Figura 6F). 

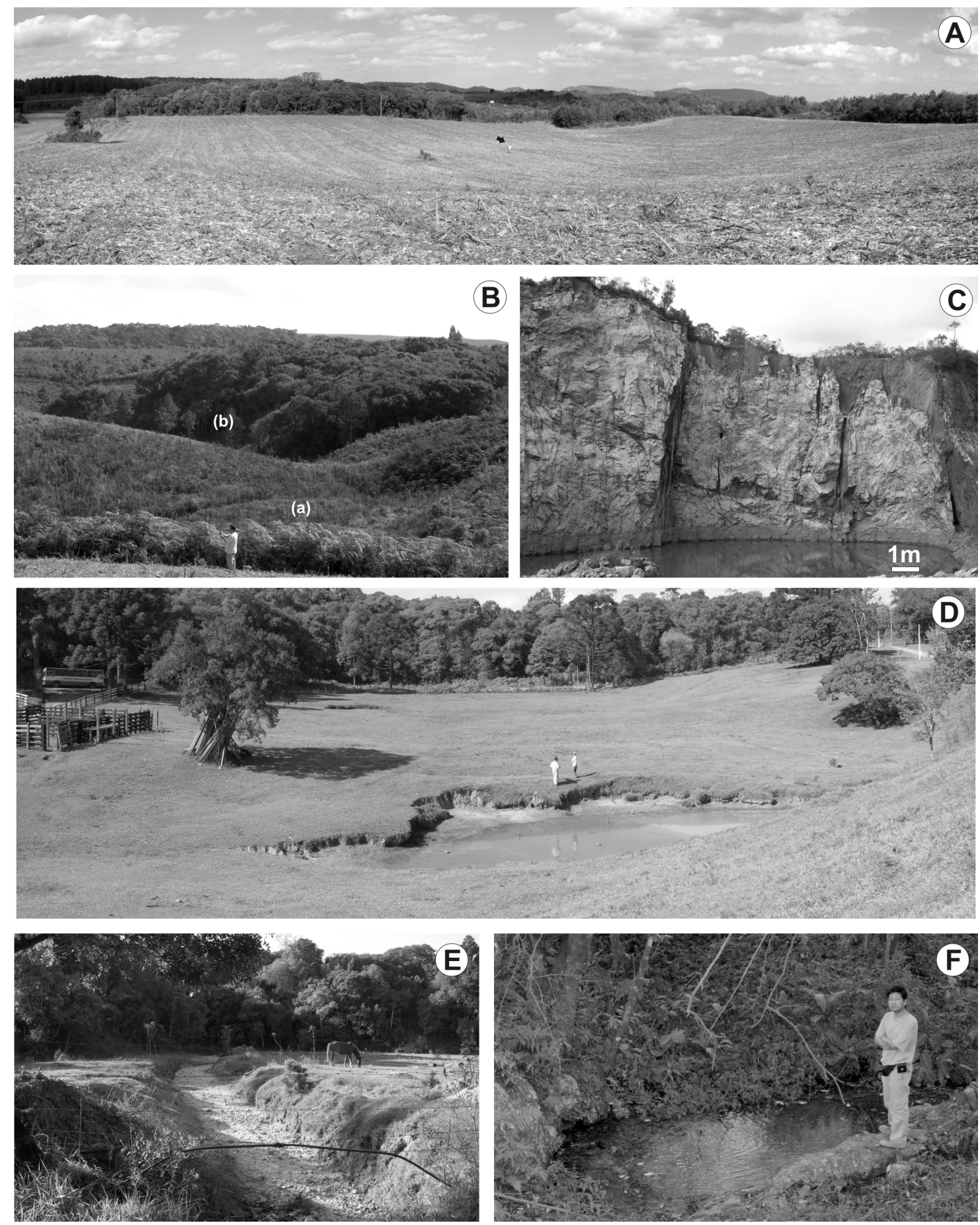

FIGURA 6: Feições cársticas da região de Bom Sucesso de Itararé. A - Depressão fechada suave colmatada por sedimentos (oeste da área urbana de Bom Sucesso de Itararé). Escala: pessoa no fundo da depressão, indicada por seta. B - Depressões fechadas (a e b) colmatadas por sedimentos (oeste da área urbana de Bom Sucesso de Itararé). C - Desenvolvimento de epicarste em pedreira abandonada, a norte da área urbana de Bom Sucesso de Itararé. D - Dolina em estágio inicial de formação, formada pelo colapso do material de cobertura (sul do município de Bom Sucesso de Itararé). E - Afluente seco do Ribeirão de José Vicente (sudoeste da área urbana de Bom Sucesso de Itararé). F - Ressurgência ao longo do Córrego Rancho do Meio, afluente do Ribeirão José Vicente (Bairro do Mato Dentro, sudoeste da área urbana de Bom Sucesso de Itararé). A localização aproximada das fotos A-F está indicada na figura 4. 


\section{CONSIDERAÇÕES FINAIS}

A partir do levantamento sistemático realizado na Faixa Itaiacoca, foi possível verificar importantes concentrações de feições cársticas em superfície - depressões fechadas, sumidouros, cones cársticos - próximas às áreas urbanas de Nova Campina e de Bom Sucesso de Itararé e no extremo sudoeste da área estudada, já no Estado do Paraná (municípios de Doutor Ulysses e Sengés). A análise morfométrica das depressões fechadas revelou que, em geral, apresentam área, perímetro, amplitude e declividade inferiores aos observados nas faixas Lajeado e André Lopes, no Vale do Ribeira; índices de circularidade são maiores. Pela área de captação das depressões fechadas autóctones e alóctones, foi possível verificar que a contribuição autóctone é expressivamente mais importante que a alóctone.

A área de abrangência das depressões fechadas do carste da Faixa Itaiacoca não está protegida por instrumentos legais, ao contrário do que ocorre na região do Alto Ribeira, onde a maior parte das feições cársticas conhecidas está inserida em unidades de conservação (Parque Estadual Turístico do Alto Ribeira - PETAR e Intervales). Ressalta-se que a interferência antrópica nesta área é diversificada (reflorestamento, agricultura, pastagem, áreas urbanizadas, aterros sanitários, represas de usinas hidrelétricas), necessitando, portanto, de diretrizes adequadas para que não ocorra o comprometimento dos recursos paisagísticos e hídricos ou o desencadeamento de problemas geotécnicos, intrínsecos à vulnerabilidade dos terrenos cársticos. Alguns problemas já se mostram presentes, tais como as enchentes periódicas na cidade de Nova Campina e os colapsos provocados por subsidência do material de cobertura em estradas e propriedades rurais.

$\mathrm{O}$ presente levantamento constitui a base para estudos de maior detalhe, integrando dados geomorfológicos, estruturais, geoquímicos e espeleológicos, que levem ao melhor entendimento da dinâmica hidrológica subterrânea da região, que, por sua vez, poderão subsidiar as ações de políticas públicas.

\section{AGRADECIMENTOS}

Ao Grupo de Estudos Espeleológicos do Paraná (GEEP/AÇUNGUI) e ao Grupo Pierre Martin de Espeleologia (GPME ) pela cessão de informações referentes às cavidades naturais da região.

\section{REFERÊNCIAS}

CAMPANHA, G.A.C. 1991. Tectônica proterozóica no alto e médio Vale do Ribeira, estados de São Paulo e Paraná. Tese de Doutoramento, Instituto de Geociências, Universidade de São Paulo, 295 p.

EPA (U.S. ENVIRONMENTAL PROTECTION AGENCY). 2002. A lexicon of cave and karst terminology with special reference to environmental karst hydrology. National Center for Environmental Assessment Washington Office, Office of Research and Development, Washington, DC 20460, EPA/600/R-02/003, 214 p.

FERRARI, J.A.; HIRUMA, S.T.; KARMANN, I. 1998. Caracterização morfométrica de uma superfície cárstica do Vale do Ribeira, São Paulo (Núcleo Caboclos - PETAR). Revista do Instituto Geológico, 19(1/2): 9-17.

FORD, D. \& WILLIAMS, P. 1989. Karst geomorphology and hidrology. Chapman \& Hall, 601 p.

GEEP/AÇUNGUI (Grupo de Estudos Espeleológicos do Paraná). 1999. Levantamento, conservação e manejo do patrimônio espeleológico do Município de Doutor Ulysses - PR. Curitiba, Convênio MMA/FNMMA 055/97, 121 p. + anexos.

GENTHNER, C.; SILVA DA ROCHA, L.F.; OSATO, E.; RABELO, L. 2001. Speleological characterization of the Casa de Pedra Karst System, Doutor Ulysses PR/Brazil. In: SBE, Speleo Brazil 2001, Brasília, Abstract.

GPME (Grupo Pierre Martin de Espeleologia). 2005. Relatório de atividades realizadas $-\mathrm{Fe}-$ vereiro 2005. www.gpme.org.br, 7 p.

HIRUMA, S.T.; FERRARI, J.A.; AMARAL, R. 2007. Caracterização morfométrica dos terrenos cársticos das bacias dos rios Ribeira de Iguape e Paranapanema. In: Redespeleo Brasil, Encontro Brasileiro de Estudos do Carste, 2, Instituto de Geociências, Universidade de São Paulo, Resumos Expandidos e Simples, 47-51. 
IG (Instituto Geológico - Secretaria do Meio Ambiente/SP). Caracterização dos terrenos cársticos das bacias dos rios Ribeira e Paranapanema e sua vulnerabilidade frente a processos erosivos e atividades minerárias. Projeto de pesquisa, inédito.

KARMANN, I. 1994. Evolução e dinâmica atual do sistema cárstico do alto vale do rio Ribeira de Iguape, sudeste do Estado de São Paulo. Tese de Doutoramento, Instituto de Geociências, Universidade de São Paulo, São Paulo, 228 p.

KARMANN, I. \& FERRARI, J.A. 2002. Carste e cavernas do Parque Estadual Turístico do Alto Ribeira (PETAR), SP: Sistemas de cavernas com paisagens subterrâneas únicas. In: C. Schobbenhaus, D.A. Campos, E.T. Queiroz, M. Winge, M.L.C. Berbert-Born (ed.) Sítios Geológicos e Paleontológicos do Brasil, DNPM/SIGEP, p. 401-414.

KARMANN, I. \& SANCHEZ, L.E. 1979. Distribuição das rochas carbonáticas e províncias espeleológicas do Brasil. Espeleotema, 13: $105-167$.

KLIMCHOUK, A. 2004. Towards defining, delimiting and classifying epikarst: its origin, processes and variants of geomorphic evolution. In: W.K. Jones, D.C. Culver, J. Herman (ed.) Epikarst. Proc. of the Symposium held October 1 through 4, 2003, Sheperdstown, West Virginia, USA. Karst Water Institute Special Publication, 9: 23-35.
OLIVEIRA, J.B.; CAMARGO, M.N.; ROSSI, M.; CALDERANO FILHO, B. 1999. Mapa pedológico do Estado de São Paulo - Legenda Expandida. Campinas: Instituto Agronômico/SAA - SP, Rio de Janeiro: Centro Nacional de Pesquisa de Solos/EMBRAPA, $64 \mathrm{p}$.

PONÇANO, W.L.; CARNEIRO, C.D.R.; BISTRICHI, C.A.; ALMEIDA, F.F.M.; PRANDINI, F.L. 1981. Mapa geomorfológico do Estado de São Paulo. IPT, Monografias 5, Publicação IPT 1183, vol. 1, 94 p.

SÃO PAULO (ESTADO). 2006. Resolução SMA56, de 27 de dezembro de 2006. Estabelece a gradação de impacto ambiental para fins de cobrança de compensação ambiental decorrente do licenciamento ambiental de empreendimentos de significativo impacto ambiental. Diário Oficial Poder Executivo - Seção I, 28 de dezembro de 2006, São Paulo, 116 (245): 49.

SOUZA, A.P. 1990. Mapa geológico na escala 1:50.000 e esboço da evolução tectônica e sedimentar do Grupo Itaiacoca, nas folhas Barra do Chapéu e Ouro Verde - SP/PR. Dissertação de Mestrado, Instituto de Geociências, Universidade de São Paulo, São Paulo, $200 \mathrm{p}$.

WILLIAMS, P.W. 1972. Morphometric analysis of polygonal karst in New Guinea. Geological Society of America Bulletin, 83: 761-796.

Endereço dos autores:

Silvio Takashi Hiruma, José Antonio Ferrari e Rosangela do Amaral - Seção de Geomorfologia, Instituto Geológico, Secretaria do Meio Ambiente do Estado de São Paulo, Avenida Miguel Stéfano, 3900, CEP 04301-903, Água Funda, São Paulo, SP.

E-mails: hiruma@igeologico.sp.gov.br, ferrari@igeologico.sp.gov.br, rosangela.amaral@igeologico.sp.gov.br

Rafael Fernando Honório - Graduando do curso de Geografia, Faculdade de Filosofia, Letras e Ciências Humanas - USP, São Paulo - SP

E-mail: rafaelhonorio1@yahoo.com.br 